\title{
Trace-elements in shallow marine ostracods and their calibration with environmental parameters
}

\author{
M. Rodriguez ${ }^{1,2^{*}}$, M. YASUHARA ${ }^{2,3}$, C. Not $^{1,3}$ \\ ${ }^{1}$ Department of Earth Sciences, The University of Hong \\ Kong, Pokfulam Road, Hong Kong SAR \\ (*correspondence: xamrodri@hku.hk). \\ ${ }^{2}$ Swire Institute of Marine Science, The University of Hong \\ Kong, Cape d'Aguilar Road, Shek O, Hong Kong SAR. \\ ${ }^{3}$ School of Biological Sciences, The University of Hong \\ Kong, Pokfulam Road, Hong Kong SAR.
}

Trace-element ratios of marine shells of ostracods have been successfully used as proxy of environmental conditions. Ostracods are tiny marine crustaceans that complete the calcification of calcium carbonate shells in a few days after their molt. Here, we analyze two geochemically unstudied species of shallow marine ostracods of Hong Kong, Sinocytheridea impressa and Neomonoceratina delicata, which are widely spread in marine bottom sediments of Asia and have been found in sedimentary records. We discuss the main factors controlling the uptake of different trace metals in these two ostracods, including $\mathrm{Mg}, \mathrm{Sr}, \mathrm{Na}, \mathrm{Mn}$ and $\mathrm{Fe}$. Our preliminary findings suggest a temperature control on the Mg uptake of the ostracod, with S. impressa and $N$. delicata adult specimens likely calcifying their shells during spring and autumn respectively. Moreover, these two species have lower $\mathrm{Mg} / \mathrm{Ca}$, but relatively similar calibration slopes than other species from the same superfamily. $\mathrm{Sr} / \mathrm{Ca}$ range is close to $1 \mathrm{mmol} \mathrm{mol}^{-1}$ and its use as proxy of environmental parameters in Hong Kong waters is limited. Mn is incorporated into the ostracod shell during the ostracod molt period and it is not associated to clays or Mn-oxides. A significant correlation was found between $\mathrm{Mn} / \mathrm{Ca}$ of $N$. delicata and suspended solids, which may help to evaluate the inland input of sediments into the estuarine system. $\mathrm{Fe} / \mathrm{Ca}$ is also significantly correlated with suspended solids in $N$. delicata specimens, but $\mathrm{Fe}$ associated to the contaminant phase may increase its concentration, limiting the element use. Our study suggests that the $\mathrm{Mg} / \mathrm{Ca}$ of $S$. impressa and $N$. delicata specimens is a potential proxy of water temperature at a monthly level, and together with other trace element ratios, such as $\mathrm{Mn} / \mathrm{Ca}$, may be used to perform environmental reconstructions of estuarine systems. 